\title{
Design concepts and analysis of a semi-active steering system for a passenger car
}

\author{
M B Baharom ${ }^{1}$, K Hussain ${ }^{2 *}$, and A J Day ${ }^{2}$ \\ ${ }^{1}$ Department of Mechanical Engineering, Universiti Teknologi Petronas, Malaysia \\ ${ }^{2}$ School of Engineering, Design and Technology, University of Bradford, Bradford, UK
}

The manuscript was received on 27 January 2009 and was accepted after revision for publication on 27 May 2009.

DOI: 10.1243/14644193JMBD205

\begin{abstract}
The fundamentals and preliminary analyses of an innovative future technology referred to as 'semi-active steering' (SAS) are presented in this article. The proposed steering system configuration is similar to a conventional electrical power-assisted steering with the replacement of the rigid steering shaft with a low stiffness resilient shaft (LSRS), the presence of which allows 'active control' to be performed on vehicles similar to the concept of full steer-by-wire (SBW). But, unlike SBW, the LSRS is an integral part of the system characteristics. The advantages of the semi-active system in comparison with SBW and other conventional systems are demonstrated. A mathematical model to predict the mechanical properties of the LSRS has been developed, and experiments were conducted on a medium-sized car fitted with an LSRS to verify that vehicle stability and drivability can be ensured in the event of active system failure. The results have indicated that the vehicle was stable and safe to be driven at low speeds, and is predicted to be driveable and safe at higher speeds. It is concluded that an SAS system of this type has the potential to improve the safety of SBW systems.
\end{abstract}

Keywords: steer-by-wire, simulation, safety, stability, drivability, automotive

\section{INTRODUCTION}

The introduction of active steering where control is performed in the presence of a rigid steering shaft has enabled modern steering systems to evolve into a new era where machine intervention or automatic steering can be performed during emergency manoeuvres [1] Although the technology could provide some benefits for safety and handling [2], the presence of a rigid steering shaft has always presented disadvantages in packaging and safety during front-end collisions [3, 4].

The latest most crucial evolution in steering technology is the introduction of steer-by-wire (SBW), where an electronic system replaces the mechanical connection or steering shaft entirely [5]. The main concern

\footnotetext{
${ }^{*}$ Corresponding author: School of Engineering, Design and Technology, University of Bradford, Chesham Building, Richmond Road, Bradford, West Yorkshire, BD7 1DP, UK.

email: k.hussain1@bradford.ac.uk
}

about SBW is safety in the event of system failure because a moving vehicle cannot be controlled without steering. Husain et al. [6] proposed a back-up steering shaft that could be activated using clutches for safety during system failure. However, this operated only in the event of failure and even then the presence of clutches will introduce more failure modes to the SBW system.

This article presents a brief description of the design concepts and analyses of an innovation in active steering technology for a passenger car, based on the concept of SBW but possessing additional safety features. The main objectives are to introduce the design concepts of the innovative technology and to verify the feasibility and practicality of the proposed steering system technology, which is referred to as 'semi-active steering' (SAS). The rigid steering shaft is replaced in the SAS with a low stiffness resilient shaft (LSRS) to allow steering intervention and the steering system automatically switches to either being 'conventional' or 'active' depending on the driving conditions. The LSRS is an integral part of the system characteristics. 


\section{SYSTEM CONCEPT DESIGNS}

\subsection{System basic configuration and parts descriptions}

The basic configuration of the SAS system is shown in Fig. 1. The main components of the system are the LSRS, reaction motor, power motor, sensors, and controllers. The control algorithm of the SAS system was proposed to incorporate power assistance and active control. During steady-state normal running conditions, the steering system behaves similarly to a conventional electrical power-assisted steering system. During undesired conditions such as excessive oversteer or understeer, the steering system will behave similarly to an SBW system and be able to actively intervene.

The LSRS is the main feature that forms the basis of the SAS. There are many ways in which an LSRS can be designed, one of which is by a cable that acts as a flexible shaft that is resilient to a torque along its length. The cable stiffness increases constantly with increased angle of twist up to a point at which it becomes extremely high and the maximum angle of twist is reached. The stiffness value would need to be carefully selected so that in the event of active system failure, the vehicle should be controllable and the system should meet the minimum requirement of the safety standard. The flexibility of the LSRS allows the SAS to operate a similar control strategy as implemented in an SBW system, while the resilient behaviour of the LSRS provides a packaging advantage because the steering wheel can be placed on either side of the car depending on requirements. The LSRS will also buckle during a front-end collision and thus reduce driver injury.

The reaction motor serves two main functions. The first is to track the motion of the steering wheel angle and provide variable torque to the driver in order to generate variable steering wheel effort/feel during

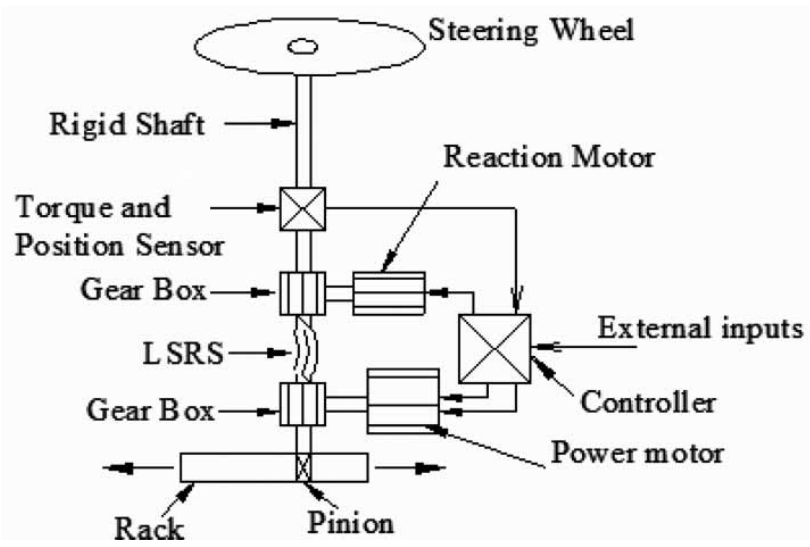

Fig. 1 Semi-active steering system schematic configuration power assist operation. The second is to minimize the disturbance at the steering wheel while simultaneously allowing acceptable disturbance to be felt at the steering wheel for steering feel purposes. This is different from the case of SBW, where the 'feel motor' function is only to simulate variable steering feel and provide adjustable steering wheel return [7].

The power motor also provides two main functions. The first is to deliver power assist to reduce driver effort during parking and manoeuvring, while the second is to control the front wheels in the event of undesired conditions. These concepts are the same as SBW, where the two functions are performed under a specific control strategy.

The functions or tasks performed by both the reaction motor and the power motor rely on the torque produced by these electric motors. For the case of the reaction motor, the total torque felt by the driver at the steering wheel is the sum of the torque intended for driver feel during power assistance and the torque from the road wheels transmitted through the LSRS. The driver will not feel unwanted steering feedback at the steering wheel (e.g. 'nibble' vibrations), because the only direct mechanical connection between the steered wheels and the steering wheel is the LSRS, and this is too flexible to be a vibration transmission path. The control system would be tuned not to respond to such vibrations since the demand is determined by the driver's required route and the vehicle dynamics, not by the instantaneous behaviour of the steered wheels. For the power motor, in order to vary the front road wheel steer angle relative to the steering wheel input angle, the control system will either increase or decrease the electrical power supplied to the power motor to provide the total torque required for assistance and control.

\subsection{Safety and the design of LSRS}

The most important safety feature of the SAS is that it has a permanent mechanical connection, namely the LSRS, between the steering wheel and the steered wheels. The LSRS is an integral part of the SAS steering system, and is always available to provide a basic steering function in case of system failure. The components are attached as permanent connections and not through clutches or meshing gears that may introduce more failure modes. Thus the system operates as a mechanical steering system in the event of active system failure. Since SBW system reliability is most strongly characterized by electronic system reliability, this represents a considerable advance in addressing the safety issues of such critically important vehicle control systems. The LSRS can be selected and designed to be flexible enough so that active control can be performed effectively in the event of even the poorest road conditions. However, in achieving 
this some design compromise may be required as the selected stiffness value of the LSRS must ensure vehicle stability and safety in the event of system failure.

The presence of the LSRS is intended to increase customer confidence in the SAS system in the same way that ABS and ESC systems are now accepted worldwide. These systems namely ABS and ESC simply revert to the conventional system in case of active system failure. One of the major concerns about the SAS is the life of the LSRS. Frequent twisting of the LSRS may lead to material fatigue which will result in system failure after a number of life cycles. For this reason, the SAS system is suitable for fitment on passenger cars where normal driving is mostly involved. In this case the LSRS is not in a state of being twisted all the time because the steering wheel angular displacement and speed are the same as the pinion.

In order to prolong the fatigue life of the LSRS, it could be designed to consist of short elements of torsion bars connected in series, an example of which is shown in Fig. 2. Each torsion bar element may possess high stiffness but when connected in series the overall stiffness will be lower. Also, when connected in series, each torsion bar will experience only a small deflection because the total deflection is the sum of the deflections of each torsion bar. The torsion bars must be designed to be attached to one another and transmit torque between each element, as shown in Fig. 2.

Steering control with the SAS is limited because the LSRS has a maximum angle of twist, which is a function of the number of turns of flexible elements, the length and diameter of the LSRS, and the material. When the LSRS reaches the maximum angle of twist, its stiffness becomes high. The general representation of this behaviour is shown in Fig. 3. The behaviour of a sudden increase in the stiffness of the LSRS after the maximum angle of twist is reached is also important as this will ensure that the vehicle is manoeuvrable or controllable during failure, especially at low speed.

\subsection{Control}

The flexibility of the LSRS allows active steer to be performed by producing a corrective steer angle to the front steered road wheels relative to the steering wheel input angle. The driver control input at the

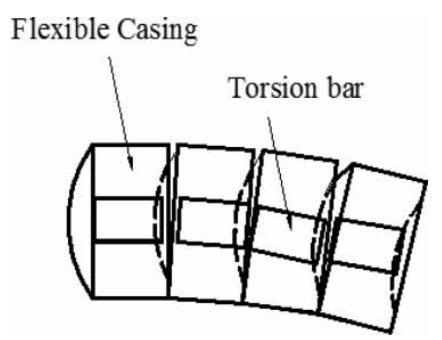

Fig. 2 Flexible shaft with series of torsion bars

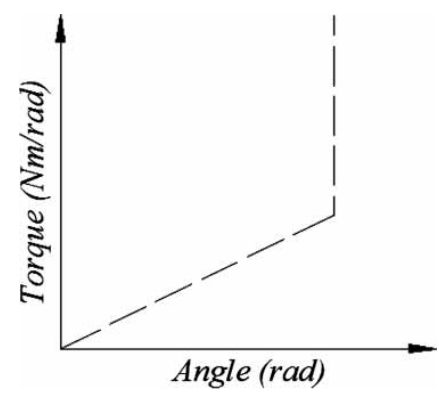

Fig. 3 Graphical representation of LSRS stiffness

steering wheel is transmitted to the steered wheels via a controlled steering motor.

With the LSRS, the operation of the power motor cannot be assured without considering its effect on other system components because the power motor is directly connected to the steering wheel via the LSRS. When the power motor rotates at a different speed to the steering wheel, a disturbance can be felt at the steering wheel. Therefore, a reaction motor is required to prevent such a disturbance from being felt by the driver by applying an equal and opposite torque to the source. Any control strategy that is implemental on SBW can also be implemented on SAS but some modification of the control formula is required in order to make a correction to the amount of torque required to operate the power motor and the reaction motor because of the presence of LSRS.

The SAS system does not require any motor to assist the steering wheel to become self-centring when the driver's hands are off the steering wheel. This is achieved by deactivating all the motors whenever there is no torque applied at the steering wheel, which overcomes the self-aligning torque. Once all the motors are deactivated, the steering system is switched to conventional steering mode. The direct mechanical linkage will then automatically ensure that the steering wheel is self-centring. Although this technique can be implemented successfully, the reaction motor may still be required to provide some kind of force feedback to the steering wheel for lane keeping assistance [8].

The steering feel is generated by the reaction motor, which applies resistive torque to the motion of the steering wheel based on the difference between the steering wheel and pinion rotation angle. The availability of mechanical connection from the steering wheel to the road wheels in the SAS allows the driver to feel directly what is happening at the road wheels. The task is performed by the reaction motor and allows acceptable disturbance to be felt at the steering wheel for the driver's purposes.

\subsection{Basic working principle}

When the steering wheel is turned during normal operation, a small deflection angle, which is the difference 
between the steering wheel rotation angle and the power motor rotation angle or the pinion rotation angle, is generated. The deflection angle would usually be very small and an amplifier is required. The deflection angle enables the torque applied at the steering wheel to be estimated. The controller receives the deflection angle signal and then operates the power motor to provide steering assistance to the driver according to the design of the power boost characteristics. The reaction motor also receives the same signal and at the same time provides some resistance to the turn of the steering wheel by providing an opposite torque. The amount of resistance varies depending on vehicle speed and steering wheel velocity; the higher the forward speed of the vehicle, the higher the amount of resistance torque generated at the steering wheel. However, as the driver turns the steering wheel at a higher speed during collision avoidance, the amount of resistance torque at the steering wheel will decrease.

During normal driving where undesired events such as understeer or oversteer are not present, the system behaves in the same way as a conventional electrical power-assisted steering system. As the controller receives a signal representing the deflection angle, it will then operate the power motor to rotate the pinion to drive the rack either to the left or to the right. In this case, the steering wheel rotation angle is almost the same as the power motor rotation angle since the deflection of the LSRS can be considered to be extremely small. The SAS system is designed such that the power motor provides all the assistance torque during cornering operations while the reaction motor provides artificial reaction torque to the driver for steering feel purposes. Any jolts or abnormalities from the road wheels can be felt directly by the driver at reduced magnitudes since there is a mechanical linkage between the steering wheel and the road wheels; and the driver's feel can be adjusted by modifying the power assistance characteristics.

In the event of understeer or oversteer, the power motor will rotate at different speeds in order to ensure that the overall steering ratio is varied for controlled steering. The LSRS provides the flexibility so that active steering can be performed to provide more or less rotation of the pinion with respect to the steering wheel input angle. The difference in speed between the steering wheel and the pinion causes the driver to feel some disturbance at the steering wheel being either assisted or resisted. In order to eliminate the disturbance from being felt at the steering wheel, the controller will receive the signal representing the rotation angle of the power motor and then operates the reaction motor to produce an equal and opposite counter torque to cancel out the generated disturbance torque. A certain amount of disturbance is allowed to be felt at the steering wheel to inform the driver that an undesired condition is happening at the road wheels.
The reaction motor should be equipped with suitable damping for smoothness of operation.

The system should be designed such that the failure of any subsystem will cause the whole system to fail in order to avoid any danger from 'part-failure' conditions. Therefore, when SAS system fails, the vehicle has the mechanical backup system, which may demonstrate degraded steering performance but is sufficient to meet the minimum safety standard.

\section{MATHEMATICAL MODELLING OF A CORNERING VEHICLE FITTED WITH A FLEXIBLE SHAFT}

The most important criteria to be analysed and validated during the preliminary stage were the selection of the LSRS and the performance of the vehicle under the implementation of LSRS. These must meet minimum safety standards to ensure that the driver is safe while controlling the vehicle before going for repair in the case of system failure. Although vehicle stability during failure is a concern, the LSRS must not be too stiff as this would require more power from the motors. Therefore, the main objective of developing the mathematical model presented here was to identify the range of acceptable LSRS stiffnesses in order to meet the safety criteria as well as the functional requirements. The predicted range of the stiffness values were therefore selected to make flexible steering shafts for the experimental work.

The derivation of the analysis is shown in Fig. 4, which shows how the steering wheel assembly, reaction motor gearing, and the power motor gearing are attached to the vehicle front steered wheel assembly.

Based on Fig. 4, the relationship between the steering wheel angle (input) and the output steered front road wheel angle can be derived. The detailed computation is similar to the case previously presented

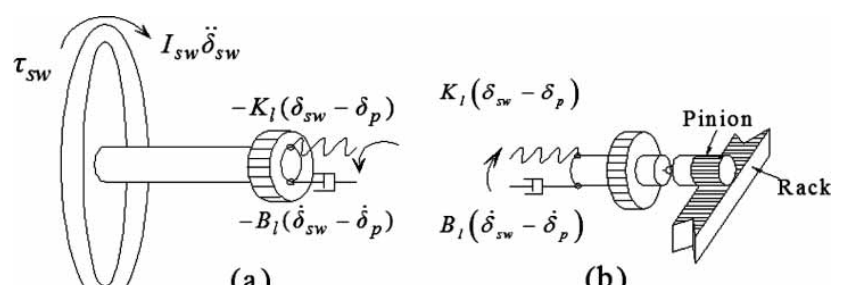

(a)

(b)

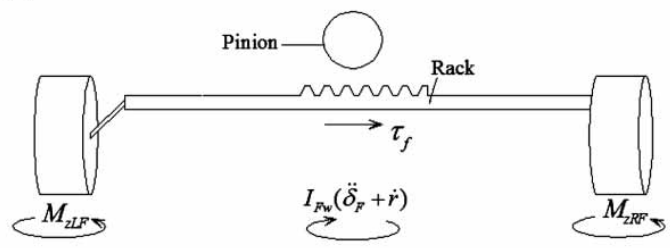

(c)

Fig. 4 Free body diagrams of SAS during system failure [9] 


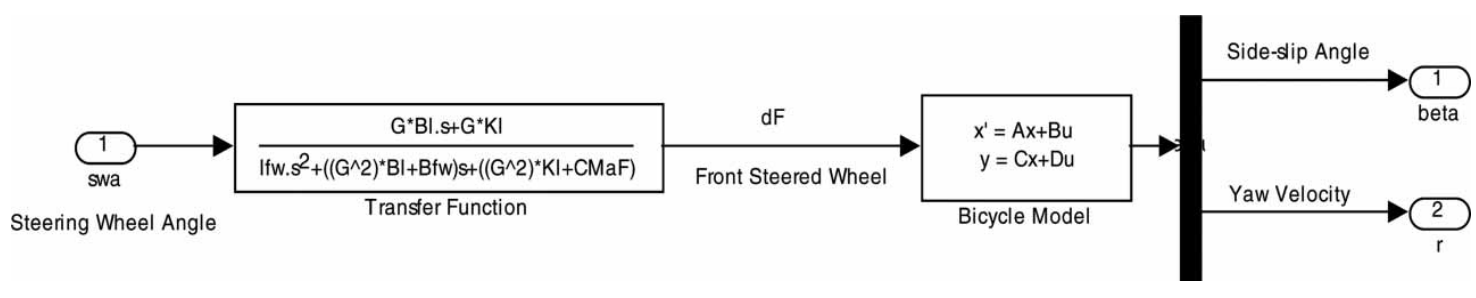

Fig. 5 SIMULINK program for SAS during system failure

by the authors [9] where the formula was derived for hydraulic power-assisted steering.

From Figs 4(b) and (c)

$$
\begin{aligned}
& G\left[B_{\mathrm{l}}\left(\overline{\dot{\delta}}_{\mathrm{sw}}-\overline{\dot{\delta}}_{\mathrm{p}}\right)+K_{\mathrm{l}}\left(\delta_{\mathrm{sw}}-\delta_{\mathrm{p}}\right)\right]-B_{\mathrm{Fw}} \dot{\delta}_{\mathrm{F}}-\tau_{\mathrm{f}}-M_{\mathrm{zF}} \\
& \quad=I_{\mathrm{Fw}}\left(\ddot{\delta}_{\mathrm{F}}+\dot{r}\right)
\end{aligned}
$$

during steady state, $\delta_{\mathrm{p}}=G \delta_{\mathrm{F}}$.

For simplicity of computation, the friction in the steering column $\tau_{\mathrm{f}}$ and the self-aligning torque $M_{\mathrm{zF}}$ are assumed to be negligible.

Rearranging and manipulating equation (1) to obtain the transfer function

$$
\begin{aligned}
& G B_{1} \bar{\delta}_{\mathrm{sw}}+G K_{\mathrm{l}} \bar{\delta}_{\mathrm{sw}} \\
& \quad=I_{\mathrm{Fw}} \ddot{\delta}_{\mathrm{F}}+\left(G^{2} B_{\mathrm{l}}+B_{\mathrm{Fw}}\right) \delta_{\mathrm{F}}+\left(G^{2} K_{\mathrm{l}}+C_{\mathrm{M} \alpha \mathrm{F}} \dot{\delta}_{\mathrm{F}}\right) \\
& \quad \Longrightarrow \delta_{\mathrm{sw}} \frac{\left(G B_{\mathrm{l}} s+G K_{\mathrm{l}}\right)}{\left[I_{\mathrm{Fw}} s^{2}+\left(G^{2} B_{\mathrm{l}}+B_{\mathrm{Fw}}\right) s+\left(G^{2} K_{\mathrm{l}}+C_{\mathrm{M} \alpha \mathrm{F}}\right)\right]} \\
& \quad \longrightarrow \delta_{\mathrm{F}}
\end{aligned}
$$

(Note: the moment of inertia of the power motor gear is neglected.)

The input to the system is the steering wheel angle $\delta_{\mathrm{sw}}$ and the output is the steer angle of the front road wheels $\delta_{\mathrm{F}}$. The corresponding output $\delta_{\mathrm{F}}$ was used as the input to the vehicle dynamics model (bicycle model). The output parameters that are used in the analysis are the yaw velocity $r$, the total lateral acceleration $a_{y}$, which is represented by $a_{y}=\dot{\beta} V_{x}+r V_{x}$, and the front steered wheel angle $\delta_{\mathrm{F}}$. The SIMULINK block diagram is shown in Fig. 5.

\section{ANALYSIS TO DETERMINE THE SUITABLE RANGE OF LSRS STIFFNESS}

\subsection{Analysis and results}

Prior to conducting the experimental work, the stiffness values of the flexible shafts fitted to the experimental car were determined. The selected steering wheel input angle for the experiment is shown in Fig. 6, referred to as 'step steer' analysis, and represents the worst case scenario during collision avoidance. The driver turned the steering wheel abruptly from the straight ahead position to a $90^{\circ}$ position in $0.2 \mathrm{~s}$.

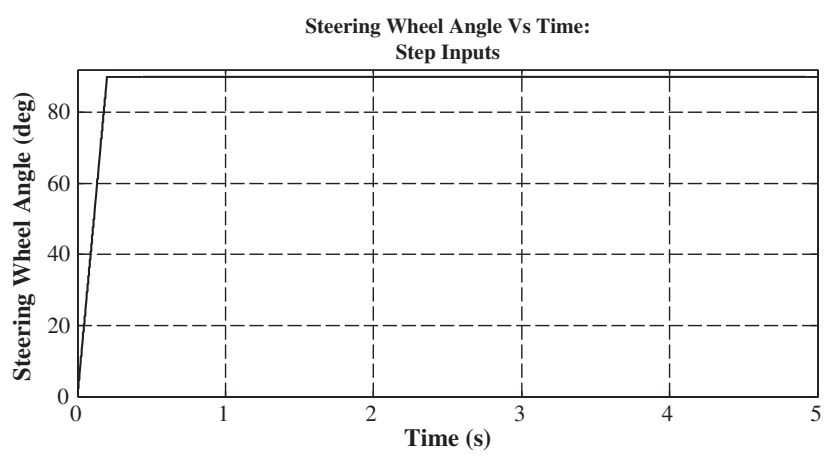

Fig. 6 Steering wheel input angle for analysis

The selected vehicle speed was $50 \mathrm{~km} / \mathrm{h}$ (30 mile $/ \mathrm{h})$ as the maximum permissible speed during the experiments for safety reasons. For the purposes of analyses, three vehicle speeds, namely 50,110 , and $0.02 \mathrm{~km} / \mathrm{h}$, were used. The speed of $110 \mathrm{~km} / \mathrm{h}$ represents the maximum average vehicle speed while $0.02 \mathrm{~km} / \mathrm{h}$ represents the minimum average manoeuvring speed during parking. The outputs from the analyses were three sets of plots of the yaw velocity versus time for each case (Figs 7 (a) to (c)). The yaw velocities were the only outputs selected for analysis because the behavioural trends found in the lateral accelerations and front steered wheel angles were similar to the behavioural trends found in the yaw velocities. The results for the conventional vehicle are also presented and overlaid for comparison.

\subsection{Discussion of results}

Based on Fig. 7(a), it can be observed that overshoot in steering response was affected by the steering shaft stiffness. Overshoot behaviour is undesirable because such a characteristic can cause a vehicle to be unstable. For lower stiffness values, overshoot started to occur when the stiffness value was $<5 \mathrm{Nm} / \mathrm{rad}$. For higher stiffness values, the overshoot started to develop when the stiffness values were $>15 \mathrm{~N} \mathrm{~m} / \mathrm{rad}$. Similar trends were also observed from the results of the average maximum and minimum vehicle speeds. Although overshoots were found in almost every case of the maximum average vehicle speed, the lowest magnitudes between the peaks and the settling values were observed to occur within the vicinity of $5-15 \mathrm{~N} \mathrm{~m} / \mathrm{rad}$. Based on these findings, the stiffness 


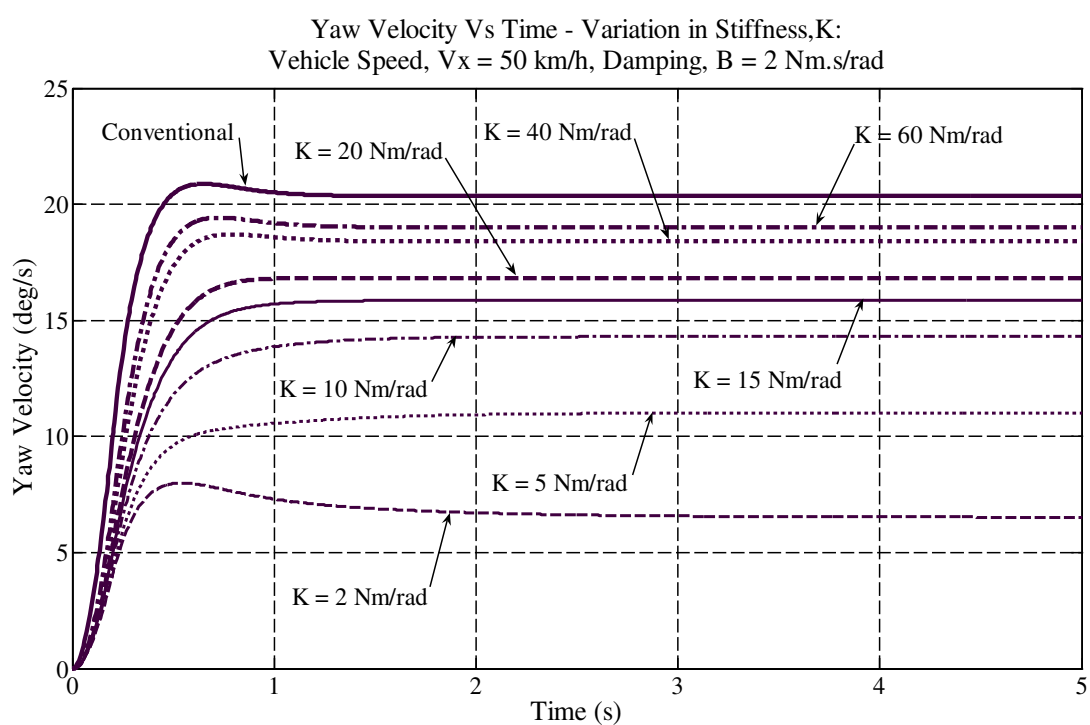

(a)

Yaw Velocity Vs Time - Variation in Stiffness, K :

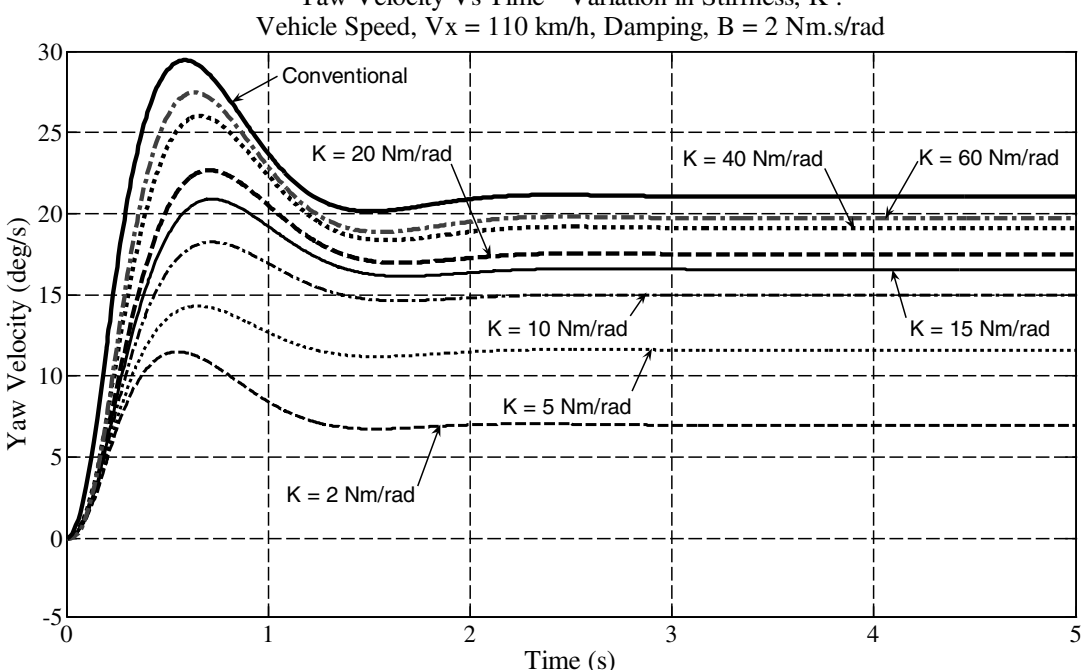

(b)

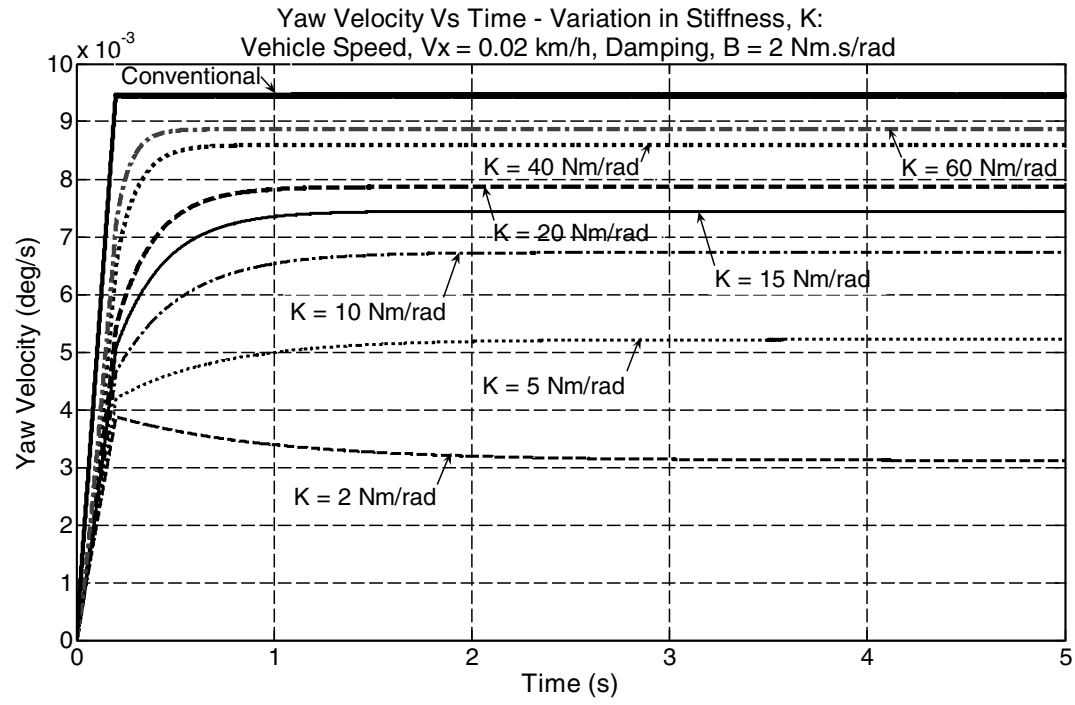

(c)

Fig. 7 (a) Output results for average vehicle speed used in experiments; (b) output results for maximum average vehicle speed; and (c) output results for minimum average vehicle speed (parking) 
values of the steering shafts for experimental work were set at 5,10 , and $15 \mathrm{~N} \mathrm{~m} / \mathrm{rad}$.

\section{EXPERIMENTAL WORK}

\subsection{Experimental set-up and procedure}

Prior to performing the experiment, preparatory work was conducted on the vehicle. The required preparations included basic safety checks, draining the steering hydraulic fluid completely from the reservoir, and installing instrumentation and a data logger.

The experiments were conducted on a small passenger car weighing $\sim 1200 \mathrm{~kg}$ including a front seat passenger and the driver. Three flexible shafts with average stiffnesses of 5,10 , and $15 \mathrm{~N} \mathrm{~m} / \mathrm{rad}$ were fabricated to replace the original intermediate steering shaft of the vehicle for the experimental work. These were fitted in turn. Since the car originally had a hydraulic power-assisted steering system, the hydraulic fluid from the vehicle was drained out completely in order to avoid additional fluid damping forces.

The data recorded from the experimental work included time, acceleration (longitudinal and lateral), vehicle speed, and distance. Steering wheel angle was measured using a 10-turn potentiometer, and all the signals from the instrumentation were logged using a DL1 logger [10]. This device had a high accuracy GPS system and a built-in accelerometer, and was powered from a $12 \mathrm{~V}$ car power socket. The sampling time interval was set to $0.01 \mathrm{~s}(10 \mathrm{~ms})$.

The experiments were conducted on a two-way single lane test track. The experimental procedure was to drive the car along a constant curve that had been laid out with an average radius of curvature of $100 \mathrm{~m}$. The car was accelerated from rest until it reached the required constant speed before the manoeuvre was introduced.

The experiment had three parts, each using one of the three steering shafts. The vehicle speed for

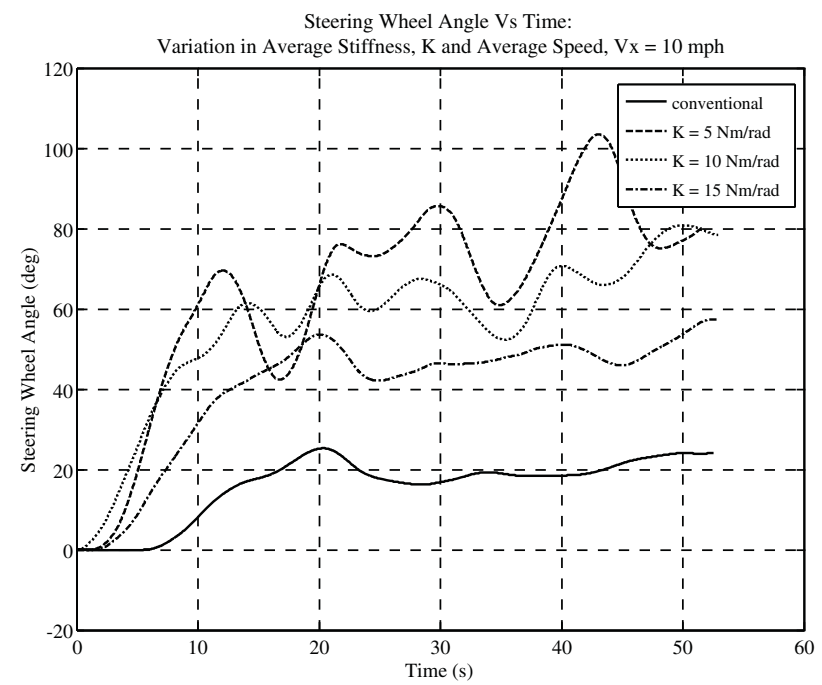

(a)

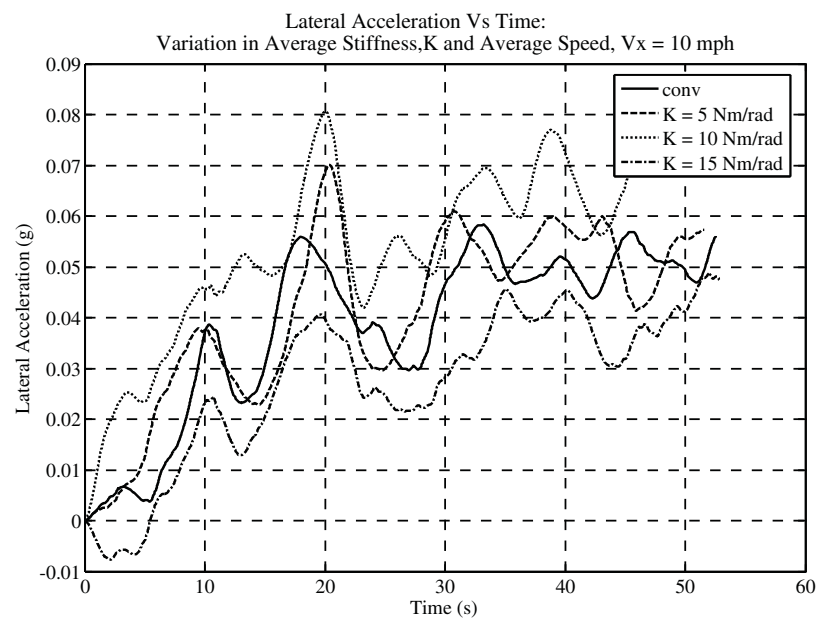

(c)

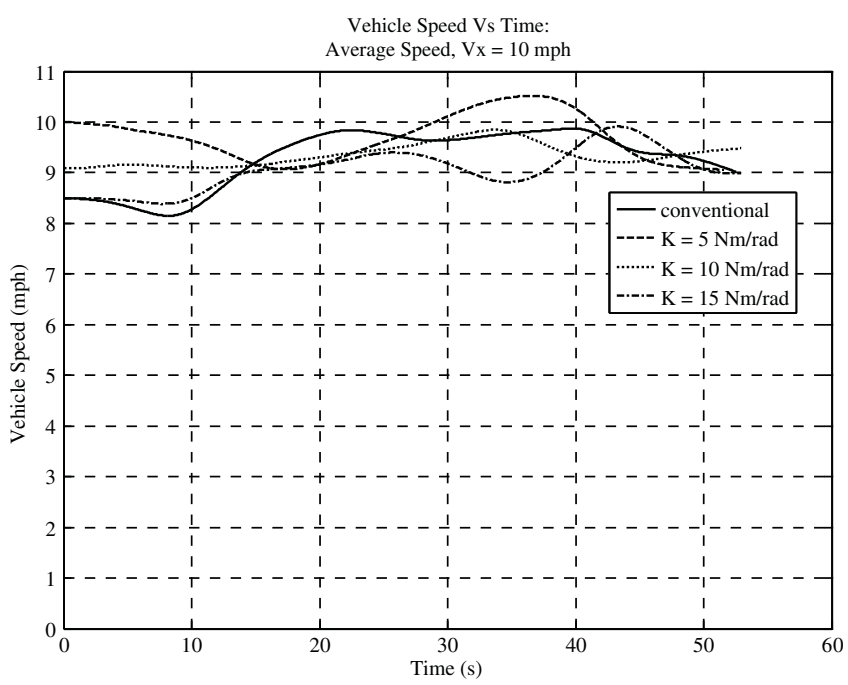

(b)

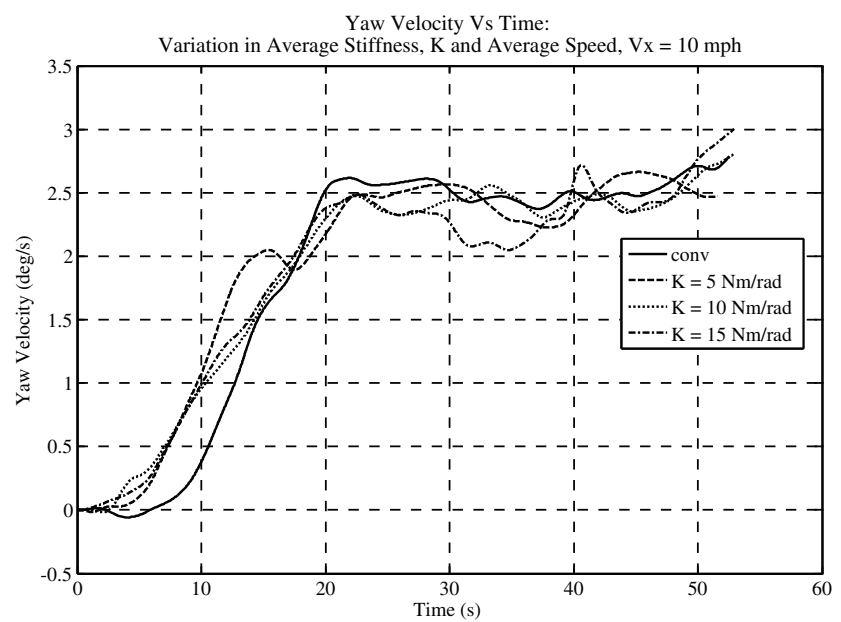

(d)

Fig. 8 Vehicle characteristics at variable stiffness $K$ and average speed $V_{x}=10 \mathrm{mile} / \mathrm{h}$ 


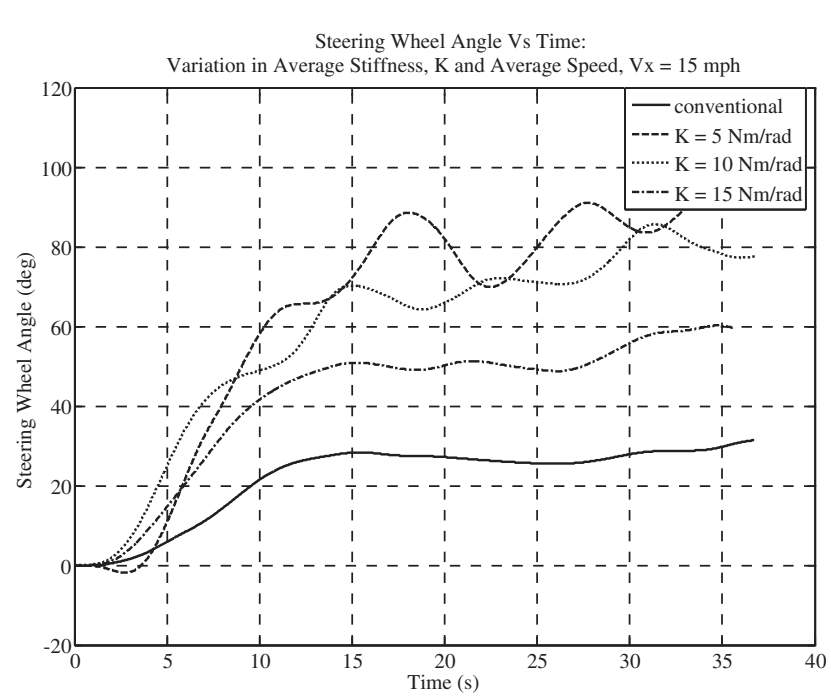

(a)

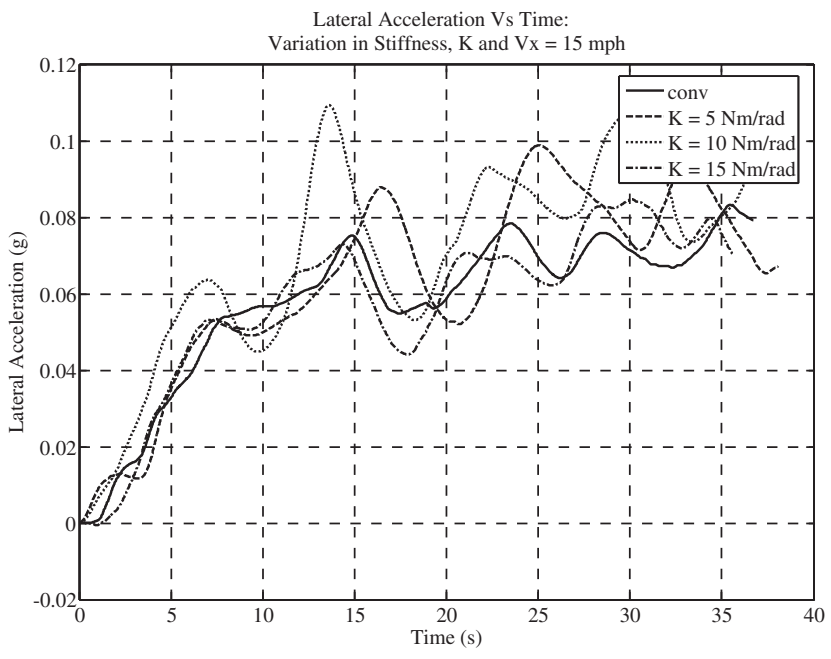

(c)

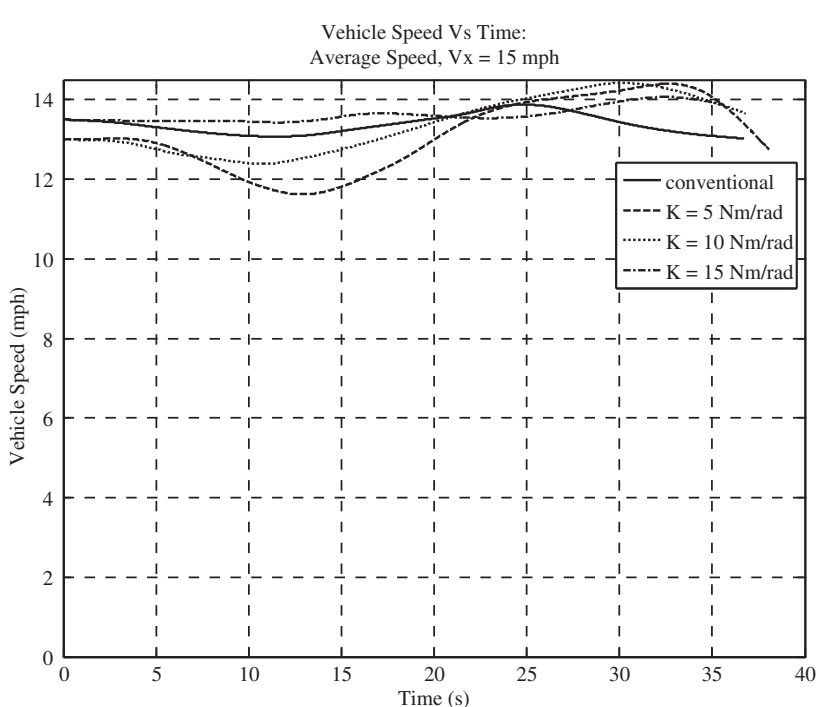

(b)

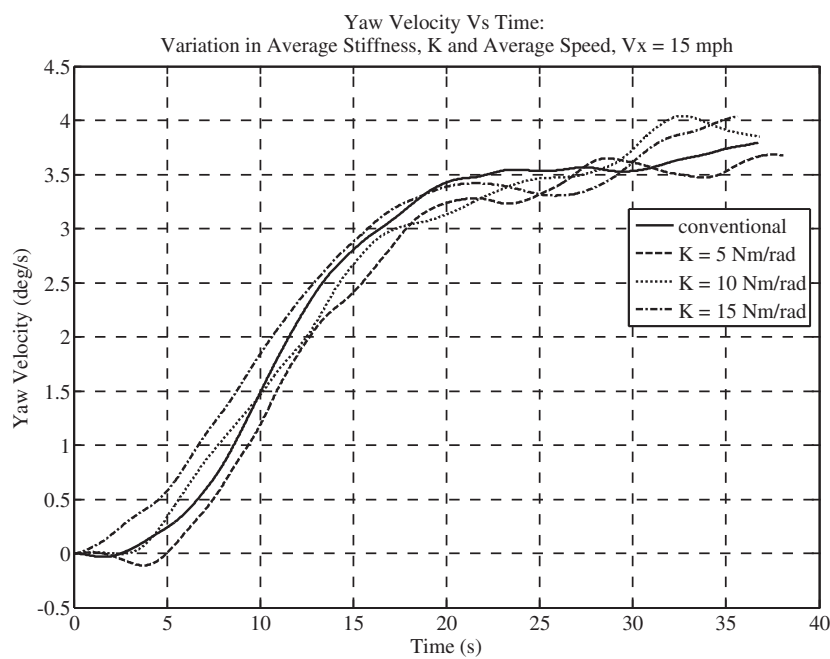

(d)

Fig. 9 Vehicle characteristics at variable stiffness $K$ and average speed $V_{x}=15 \mathrm{mile} / \mathrm{h}$

each part was limited to $15 \mathrm{~km} / \mathrm{h}$ (10 mile $/ \mathrm{h}$ ), $25 \mathrm{~km} / \mathrm{h}$ (15 mile/h), and $50 \mathrm{~km} / \mathrm{h}(30 \mathrm{mile} / \mathrm{h})$, respectively. A constant speed condition was not possible as the experimental vehicle had no cruise control system.

\subsection{Experimental results and discussion}

The purpose of the experimental work was to verify the SAS system to confirm whether the LSRS for the safety backup (which served as the backbone of the proposed design) could be implemented safely. The experimental results are presented in Figs 8 to 10 where the characteristics of parameters with varying shaft stiffness values are plotted.

In general, the test vehicle was found to be stable and safe to be driven during every experiment. Because of the flexibility of the steering shaft, which introduces variable steering ratios depending on vehicle speeds, an average driver may find that gaining familiarity with the proposed steering system is required compared to a conventional steering system. Based on the judgements of experienced drivers during the experiments, this system was acceptable in terms of steering wheel feel and no abnormalities or vibrations were encountered.

For all the lateral accelerations and yaw velocities under each speed class, it was found that the experimental vehicle fitted with steering shaft of stiffness $5 \mathrm{~N} \mathrm{~m} / \mathrm{rad}$ behaved similarly to the test car with the conventional steering system as observed from the graphical trends of the output graphs. This was also true for the same test car fitted with a steering shaft of stiffness of 10 and $15 \mathrm{Nm} / \mathrm{rad}$. The magnitudes of lateral acceleration and yaw velocity were also found to increase with an increase in vehicle speed. Although slight fluctuations and variations were observed under each speed class, these factors were negligible because the vehicle speed for each 


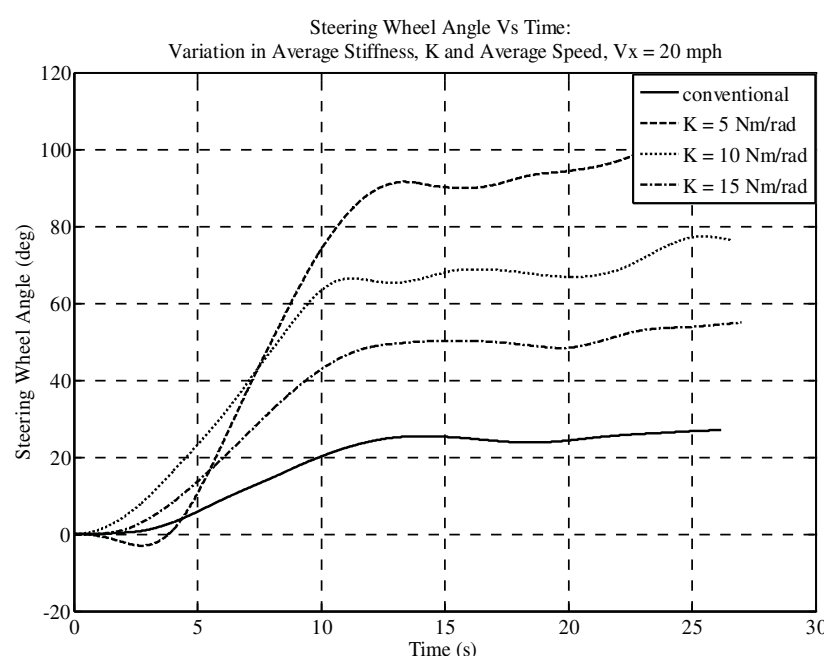

(a)

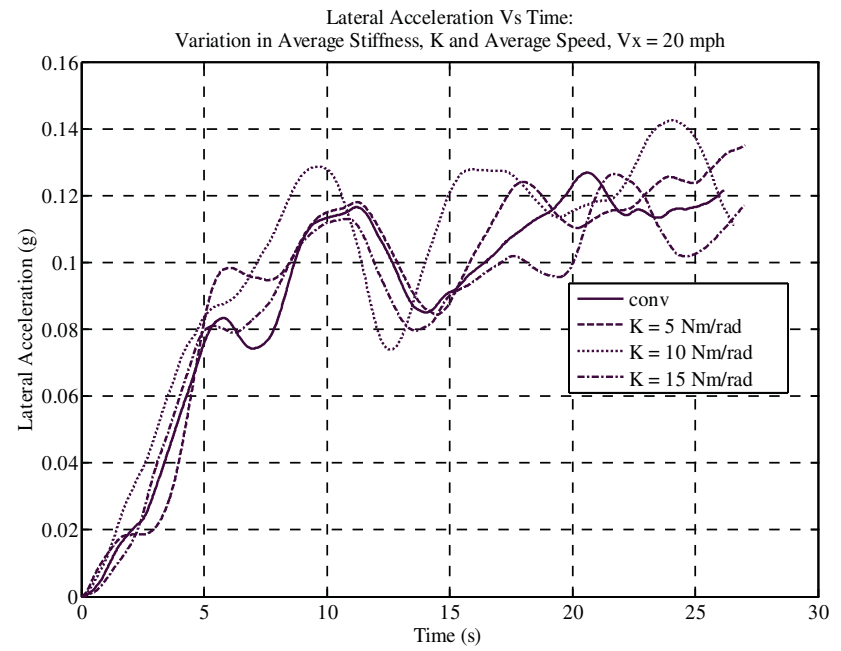

(c)

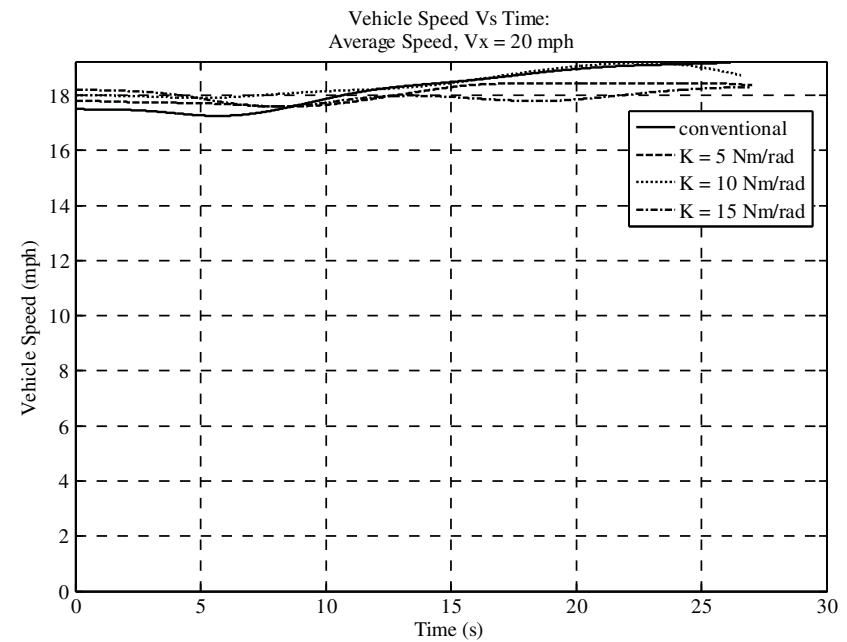

(b)

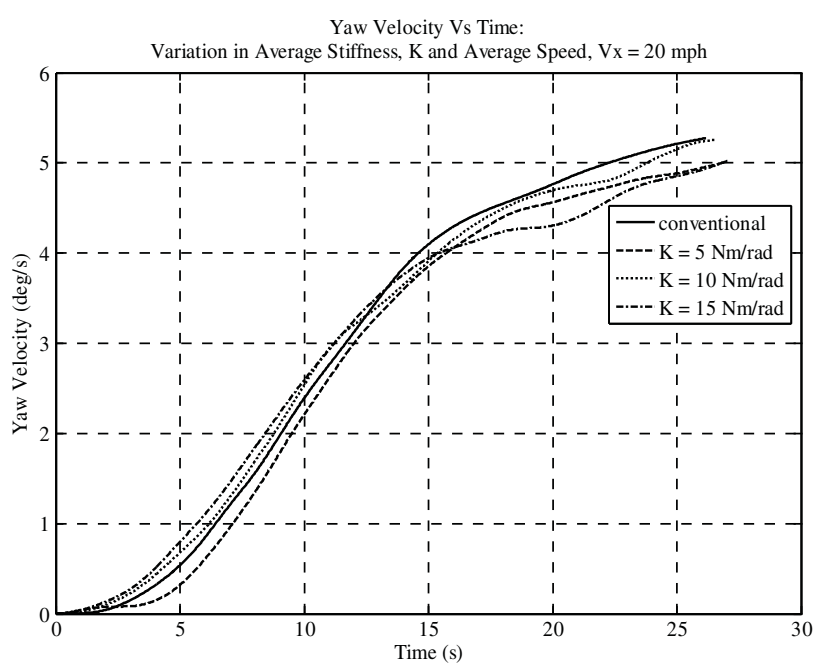

(d)

Fig. 10 Vehicle characteristics at variable stiffness $K$ and average speed $V_{x}=20 \mathrm{mile} / \mathrm{h}$

test under the same speed class was not constant. Therefore, the experimental results confirmed that the steering shaft stiffness of $5 \mathrm{~N} \mathrm{~m} / \mathrm{rad}$ (the lowest among all the selected stiffnesses) was within the minimum acceptable range required by the test car for stability and safety in case of SBW system failure. Better results for vehicle stability could be obtained with stiffness values $>5 \mathrm{~N} \mathrm{~m} / \mathrm{rad}$.

From all the graphs of steering wheel angle versus time in each speed class, it can be observed that the lower the steering shaft stiffness, the higher the steering wheel angle. This is because of the flexibility of the steering shaft; more angle of twist is required to develop the required torque for turning.

It can also be seen that the lower the vehicle speed, the more the fluctuations observed in the steering wheel angle characteristics. This is because at low speed, the self aligning torque is also very low. When the self-aligning torque is low, the moving vehicle will tend to be unstable and try to deviate from a straightline path. As a result, the driver needs to turn and control the steering wheel in order to ensure a straight path is maintained.

With the increase in flexibility, more steering adjustments were required for the low steering shaft stiffness than for the more rigid ones. This could be improved at higher vehicle speeds where the self-aligning torque alone is high enough to maintain a vehicle in a straight path. These phenomena can be confirmed where the lateral accelerations and yaw velocities are more consistent for all categories in the speed class $50 \mathrm{~km} / \mathrm{h}$ as compared to the characteristics found in the speed class $15 \mathrm{~km} / \mathrm{h}$.

Although at higher vehicle speeds, a moving vehicle tends to be more stable when moving in a straight line, further experiments involving higher vehicle speeds need to be performed in future work because the actual behaviour of the car at higher speed could not be measured, only predicted. 


\section{CONCLUSIONS}

It can be concluded that the proposed LSRS is safe to be driven in the event of active system failure of the proposed SAS system. The experimental results have shown that a test vehicle fitted with a flexible shaft of stiffness as low as $5 \mathrm{Nm} / \mathrm{rad}$ provided stability and was safe to drive during cornering tests, based on the graphical trends of the output results, namely lateral accelerations and yaw velocities that behaved similarly to the same test car fitted with a conventional steering system.

The SAS for a passenger car presented in this article has more advantages than the SBW in terms of safety aspects. In the event of active system failure, the LSRS readily provides a basic steering function. The SAS system can also offer the same benefits as SBW, and it is concluded that the SAS has advantages that could lead it being fitted to passenger cars in the future.

\section{REFERENCES}

1 Ackermann, J. and Bunte, T. Automatic car steering control bridges over the driver reaction time. Kybernetika, 1997, 1, 61-74.

2 Ackermann, J. Active steering for better safety, handling and comfort. In Proceedings of the Advances in Vehicle Control and Safety, Amiens, France, 1-3 July 1998, pp. 1-10.

3 Yih, P. Steer-by-wire: implications for vehicle handling and safety. PhD Thesis, Stanford University, 2005, available from http://gradworks.umi.com/31/53/ 3153217.html

4 Oh, S., Chae, H., Yun, S., and Han, C. The design of a controller for the steer-by-wire system. JSME Int.J., Ser. C, 2004, 47(3), 896-907.

5 Cesiel, D., Gaunt, M. C., and Daugherty, B. Development of a steer-by-wire system for the GM sequel. SAE technical paper 2006-01-1173, 2006.

6 Husain, M., Daugherty, B., and Oynoian, J. Motor vehicle steering system. US Pat. Application Publication, Pub. no.: US 2004/0262073 Al, Appl. no.: 10/610,123, 2004.

7 Yih, P. and Gerdes, J. C. Steer-by-wire for vehicle state estimation and control. In Proceedings of the International Symposium on Advanced Vehicle Control (AVEC), Arnhem, The Netherlands, 2004.
8 Switkes, J. P., Rossetter, E. J., Coe, I. A., and Gerdes, J. C. Handwheel force feedback for lanekeeping assistance: combined dynamics and stability. In Proceedings of the International Symposium on Advanced Vehicle Control (AVEC), Arnhem, The Netherlands, 2004.

9 Baharom, M. B., Hussain, K., and Day, A. J. Mathematical modelling of a cornering vehicle fitted with hydraulicpower assisted steering. In Proceedings of the FISITA 2006, Japan, 2006, F2006V019.

10 Race-Technology (n.d.), available from www.racetechnology.com/description_2_47.html, 2009.

\section{APPENDIX}

\section{Notation}

\begin{tabular}{|c|c|}
\hline$a, b$ & $\begin{array}{l}\text { distance from c.g. to front contact } \\
\text { patch, rear contact patch }(\mathrm{m})\end{array}$ \\
\hline$a_{y}$ & total lateral acceleration $\left(\mathrm{m} / \mathrm{s}^{2}\right)$ \\
\hline$B_{1}$ & $\begin{array}{l}\text { steering shaft damping coefficient } \\
\text { (N m s/rad) }\end{array}$ \\
\hline$B_{\mathrm{Fw}}$ & $\begin{array}{l}\text { front wheel assembly damping } \\
\text { coefficient ( } \mathrm{N} \mathrm{m} \mathrm{s/rad)}\end{array}$ \\
\hline$C_{\mathrm{F} \alpha \mathrm{F}} ; C_{\mathrm{F} \alpha \mathrm{R}}$ & $\begin{array}{l}\text { front and rear cornering coefficients } \\
(\mathrm{N} / \mathrm{rad})\end{array}$ \\
\hline$C_{\mathrm{M} \alpha \mathrm{F}}$ & $\begin{array}{l}\text { self-aligning torque coefficient } \\
(\mathrm{N} \mathrm{m} / \mathrm{rad})\end{array}$ \\
\hline$G$ & steering ratio \\
\hline$I_{\mathrm{Fw}}$ & $\begin{array}{l}\text { moment of inertia of front wheel } \\
\text { assembly }\left(\mathrm{kg} \mathrm{m}^{2}\right)\end{array}$ \\
\hline$I_{\mathrm{zz}}$ & yaw moment of inertia $\left(\mathrm{kg} \mathrm{m}^{2}\right)$ \\
\hline$K_{1}$ & $\begin{array}{l}\text { steering shaft torsional stiffness } \\
(\mathrm{N} \mathrm{m} / \mathrm{rad})\end{array}$ \\
\hline$m$ & total vehicle mass (kg) \\
\hline$M_{\mathrm{zF}}$ & self-aligning torque $(\mathrm{N} \mathrm{m})$ \\
\hline$r, \dot{r}$ & $\begin{array}{l}\text { yaw velocity, yaw acceleration ( } \mathrm{rad} / \mathrm{s} \text {, } \\
\left.\mathrm{rad} / \mathrm{s}^{2}\right)\end{array}$ \\
\hline$V_{x}$ & vehicle longitudinal speed $(\mathrm{km} / \mathrm{h})$ \\
\hline$\alpha_{\mathrm{F}}$ & front slip angle $\left(^{\circ}\right)$ \\
\hline$\beta$ & side-slip angle $\left(^{\circ}\right)$ \\
\hline$\delta_{\mathrm{sw}}$ & steering wheel angle $\left(^{\circ}\right)$ \\
\hline$\delta_{\mathrm{F}}$ & average front steered wheel angle $\left(^{\circ}\right)$ \\
\hline$\delta_{\mathrm{p}}$ & pinion rotation angle $\left(^{\circ}\right)$ \\
\hline$\tau_{\mathrm{f}} ; F_{\mathrm{cf}}$ & $\begin{array}{l}\text { friction torque and friction force on } \\
\text { steering wheel }(\mathrm{N} \mathrm{m}, \mathrm{N})\end{array}$ \\
\hline
\end{tabular}

